\title{
Adherence to food-based dietary guidelines among adolescents in Germany according to socio-economic status and region: results from Eating Study as a KiGGS Module (EsKiMo) II
}

\author{
Anna-Kristin Brettschneider, Clarissa Lage Barbosa, Marjolein Haftenberger, \\ Franziska Lehmann and Gert BM Mensink* \\ Department of Epidemiology and Health Monitoring, Robert Koch Institute, General-Pape-Str. 62-66, Berlin 12101, \\ Germany
}

Submitted 19 November 2019: Final revision received 23 November 2020: Accepted 5 January 2021: First published online 11 January 2021

\begin{abstract}
Objective: Dietary habits developed during childhood and adolescence are likely to continue into adulthood. An unbalanced diet may cause nutrient deficiencies and excessive energy intake; these enhance the risk for developing overweight and obesity and their co-morbidities. In the present analysis, food consumption of adolescents is described and evaluated against German food-based dietary guidelines with special focus on socio-economic status (SES) and region of residence.

Design: Within the 'German Health Interview and Examination Survey for Children and Adolescents' (KiGGS Wave 2), the cross-sectional 'Eating Study as a KiGGS Module' (EsKiMo II) was conducted from 2015 until 2017 to provide data about dietary behaviour.

Setting: Germany.

Participants: 1353 adolescents aged 12-17 years from a nationwide representative sample with food consumption data from computer-assisted dietary history interviews.

Results: The median consumption of fruits, vegetables, starchy foods and milk/dairy products among adolescents in Germany was below the recommendation. The median consumption of both meat/meat products and unfavourable foods, like confectionery, which should be consumed sparingly, was about 1.5 times the recommended amount. The total amount of beverages consumed by most adolescents was above the minimum amount recommended. Soft drink consumption of adolescents with a low SES was three to five times higher than soft drink consumption of adolescents with a high SES.

Conclusions: The results indicate the need for an improvement of dietary habits among adolescents in Germany. Further approaches to promote healthy diets in Germany should be continued, and the focus on social inequalities should be strengthened.
\end{abstract}

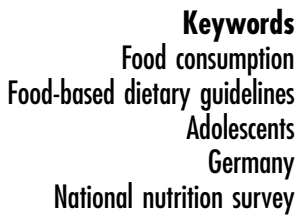

There are many known relationships between diet and health outcomes ${ }^{(1)}$. An unbalanced diet may cause nutrient deficiencies and excessive energy intake which can increase the risk of becoming overweight or obese. Being overweight or obese is a risk factor for various diseases such as diabetes mellitus type 2 or CVD. In addition, being overweight or obese in childhood is very likely to be continued into adulthood ${ }^{(2)}$. Taste preferences and dietary habits developed during childhood may also last for a lifetime ${ }^{(3,4)}$. Associations between social disparities and health behaviour among adolescents have been observed; a lower socio-economic status (SES) is associated with less participation in sports, poorer diets and higher prevalence rates for being overweight and obese ${ }^{(5-7)}$. International and national research focusing on dietary behaviour shows that there is lower consumption of fruit ${ }^{(8,9)}$ and vegetables ${ }^{(8-10)}$ among adolescents with a low SES compared with adolescents with a high SES. Among adolescents with a low SES, the consumption of sugar-sweetened 
beverages ${ }^{(8,11-13)}$ and fast food ${ }^{(10,14)}$ is higher than that of their counterparts with a high SES.

Food consumption habits are changing continuously due to changes in the food supply and other reasons that include an extension of the range of products as well as changes in living conditions. For example, the all-day school system in Germany has been expanded in the last years. Therefore, school meals have an increasing influence on food consumption among children and adolescents $^{(15)}$. In former East Germany, all-day schools were more common than in former West Germany; therefore, the utilisation of school meals among children and adolescents was also more common ${ }^{(15)}$. Therefore, it is still interesting to compare food consumption in former East and West Germany almost 30 years after the reunification.

National representative dietary surveys provide relevant information on food consumption of the general population and specific groups. Such information, including deficits in food consumption in specific population groups, is needed to identify relevant fields of action for public health interventions. This is relevant for decision-makers in the field of public health nutrition. The 'German Health Interview and Examination Survey for Children and Adolescents' (KiGGS) is part of the national health monitoring system of the Robert Koch Institute ${ }^{(16)}$. Within the KiGGS baseline survey (2003-2006), a study with indepth focus on nutrition, the 'Eating Study as a KiGGS Module' (EsKiMo), was conducted in 2006(17). About a decade later, EsKiMo II (2015-2017) was conducted as part of KiGGS Wave 2. This newly available information about food consumption of children and adolescents living in Germany may help to identify deficits and excesses in food consumption and risk groups ${ }^{(18,19)}$. The aim of this analysis is to describe the food consumption among 12- to 17-yearold adolescents in general and to stratify it by SES as well as by the region of residence and to evaluate their food consumption in relation to German food-based dietary guidelines according to the concept of the Optimized Mixed Diet $(\mathrm{OMD})^{(20)}$.

\section{Methods}

\section{Study design}

EsKiMo II was implemented within the second wave of KiGGS - KiGGS Wave 2 and conducted between 2015 and 2017 with the aim of providing representative data on food consumption and nutritional status among children and adolescents living in Germany. For EsKiMo II, an age- and sex-stratified sample of 2644 children and adolescents aged 6-17 years was drawn from the study sample of the cross-sectional part from KiGGS Wave 2. Since different instruments were used to assess food consumption depending on participants' age ${ }^{(18,19)}$, the present analysis is restricted to 1353 adolescents aged from 12 to 17 years.

\section{Dietary assessment}

Participants aged from 12 to 17 years were interviewed about their food consumption during the past 4 weeks using the software DISHES (Dietary Interview Software for Health Examination Studies) which is based on a modified dietary history method developed by the Robert Koch Institute $^{(17,21)}$. The interviews were conducted face-to-face by trained nutritionists during home visits. Following a daily meal structure (breakfast, mid-morning snack, lunch, mid-afternoon snack, dinner, small late meal and snacks throughout the day), the consumption frequencies and portion sizes of all foods consumed were recorded. Tableware models and a picture book of portion sizes ${ }^{(22,23)}$ were used to assist in the estimation of portions. A validation study among adults showed that differences in macronutrient intake between DISHES and 3-d dietary records and 24-h recalls were within an acceptable range for assessing food consumption in epidemiological studies ${ }^{(21)}$. Estimation of food consumption using DISHES showed fairly good agreement with a FFQ among children ${ }^{(24)}$. For the selection of food items, the German Nutrient Data Base (Bundeslebensmittelschlüssel, Max Rubner Institute) Version 3.02 was integrated in the DISHES software.

\section{Food group quantities}

Quantities were calculated on the basis of the amount of foods as they were consumed (e.g. cooked, fried, raw). Composed dishes, which could not be unequivocally assigned to one food group, were decomposed into their ingredients, and these were assigned to the corresponding food group. The mean daily amount of each food consumed was obtained by multiplying the consumption frequency by the portion amount and dividing this by 28 ( 4 weeks $\stackrel{\wedge}{=} 28 \mathrm{~d}$ ). The daily amounts consumed were summarised in food groups. For solid foods, fourteen different groups (bread, savoury baked goods; grain, pasta, rice; breakfast cereals; salty snacks; vegetables; fruits; potatoes; eggs; fats and oils; milk/dairy products, cheese, curd; meat/meat products; fish; confectionery, cake; other food items) and for beverages, six groups (tea; coffee; juice; soft drinks; alcoholic beverages; water) were constructed. Table 1 gives an overview of the food groups.

\section{Food-based dietary guidelines for children and adolescents in Germany}

The food consumption in EsKiMo II was compared with the OMD recommendations of $2017^{(20)}$. Within the concept of $\mathrm{OMD}$, the German nutrient recommendations (D-A-CH reference values) were translated into sex- and age-specific food-based dietary guidelines for children and adolescents $^{(20)}$. The recommended age-specific amounts were derived for eleven food groups, considering an energy requirement for a low level of physical activity (PAL $1.4)^{(20)}$. The foods reported in EsKiMo II were summarised 
Table 1 Description of the analysed food groups

\begin{tabular}{ll}
\hline Main group & Examples \\
\hline Bread, savoury baked goods & Bread, bread rolls, bread products, savoury baked goods \\
$\begin{array}{l}\text { Grain, pasta, rice } \\
\text { Breakfast cereals }\end{array}$ & Grain, flours, grain products, rice, noodles \\
Salty snacks & Cornflakes, muesli, cereals \\
Vegetables & Crisps, crackers and salted sticks \\
Fruits & Cooked and raw vegetables (excluding potatoes), legumes, vegetable products \\
Potatoes & Cooked and raw fruits, fruit products \\
Eggs & Potatoes and potato products \\
Fats and oils & Butter, lard, margarine, plant oils \\
Milk/dairy products, cheese, curd & Milk, dairy products, cheese, cream cheese, curd \\
Meat/meat products & Poultry, meat, offal, mollusc, raw, cooked and pre-cooked sausage \\
Fish & Fatty fish, lean fish, crustaceans and shellfish \\
Confectionery, cake & Sugar, sweetener, sweet spreads, sweets, ice cream, chocolate, pralines, confectionery \\
& products, desserts, sweet sauces, cakes, biscuits, waffles \\
Tea & Green tea, black tea, herbal tea, fruit tea \\
Coffee & Coffee, coffee-based drinks, coffee substitutes \\
Juice & Fruit and vegetable juice, fruit-based drinks, nectar, smoothies \\
Soft drinks & Sugar-sweetened beverages, low calorie drinks, isotonic drinks, non-alcoholic beer \\
Alcoholic beverages & Beer, wine, liquor \\
Water & Sparkling water, tap water, water as ingredient \\
\hline
\end{tabular}

Table 2 Recommendations for food consumption quantities according to the food-based dietary guidelines ${ }^{(20)}$

\begin{tabular}{|c|c|c|c|c|c|}
\hline \multirow[b]{2}{*}{ Age } & \multirow[b]{2}{*}{12 years } & \multicolumn{2}{|c|}{$13-14$ years } & \multicolumn{2}{|c|}{$15-17$ years } \\
\hline & & Girls & Boys & Girls & Boys \\
\hline \multicolumn{6}{|l|}{ Foods to be consumed plenty } \\
\hline Beverages $(\mathrm{ml} / \mathrm{d})$ & 950 & 1000 & 1200 & 1100 & 1400 \\
\hline Vegetables ( $\mathrm{g} / \mathrm{d})$ & 300 & 320 & 390 & 340 & 440 \\
\hline Fruits $(\mathrm{g} / \mathrm{d})$ & 280 & 300 & 360 & 310 & 410 \\
\hline Bread/(breakfast) cereals (g/d) & 180 & 190 & 230 & 200 & 260 \\
\hline Potatoes/rice/pasta (g/d) & 160 & 170 & 200 & 180 & 230 \\
\hline \multicolumn{6}{|l|}{ Foods to be consumed moderately } \\
\hline Milk/dairy products* $(\mathrm{g} / \mathrm{d})$ & 470 & 490 & 600 & 520 & 680 \\
\hline Meat/meat products $(\mathrm{g} / \mathrm{d})$ & 50 & 50 & 60 & 50 & 70 \\
\hline Eggs (pieces/week) & $2-3$ & 3 & 3 & 3 & $3-4$ \\
\hline Fish (g/week) & 90 & 100 & 110 & 100 & 130 \\
\hline \multicolumn{6}{|l|}{ Foods to be consumed sparingly } \\
\hline Oil/margarine/butter (g/d) & 30 & 30 & 35 & 30 & 40 \\
\hline Unfavourable foods (max. kcal/d†) & 180 & 200 & 230 & 190 & 260 \\
\hline
\end{tabular}

*Milk equivalents, i.e. $100 \mathrm{~g}$ milk corresponds to $100 \mathrm{~g}$ yogurt or $30 \mathrm{~g}$ cheese.

$\dagger 100 \mathrm{kcal}$ corresponds to about $20 \mathrm{~g}$ chocolate or $30 \mathrm{~g}$ jam or $45 \mathrm{~g}$ fruit cake or 10 chips or $200 \mathrm{ml}$ lemonade.

into the eleven OMD food groups. These can generally be categorised in three recommended consumption amount groups:

foods to be consumed plenty - 'beverages', 'vegetables', 'fruits', 'bread/(breakfast) cereals', 'potatoes/pasta/rice';

foods to be consumed moderately - 'milk/dairy products', 'meat/meat products', 'eggs', 'fish';

foods to be consumed sparingly - 'oil/margarine/butter', 'unfavourable foods' (sweets, pastries, sugar-sweetened beverages).

In order to evaluate food group consumption according to the concept of the OMD, for each individual, we divided the particular food group consumption by the corresponding age- and sex-specific recommendations and multiplied this by 100 . The distribution characteristics of these proportion values are presented. For the present analysis, the food groups 'bread/(breakfast) cereals' and 'potatoes/pasta/ rice' were summarised as 'starchy foods' (referring to foods with high content of complex carbohydrates). For comparison with the OMD, sugar-containing beverages were included in the food group beverages. In addition, the energies obtained from sugar-containing beverages were included in the group 'unfavourable foods'. Age- and sex-specific OMD-recommended quantities for adolescents aged 12-17 years are shown in Table 2.

\section{Socio-economic status and region of residence}

In KiGGS Wave 2, comprehensive information from participants and their parents was collected. A multidimensional SES index was derived from information provided by the 
parents about their level of education, occupational status and net income. Therefore, point scores were assigned according to the level of each status dimension ranging from 1 to a maximum of 7 , and the sum of these scores was calculated. The three equally weighted subscales of education, occupational status and income provide the basis for calculating the SES index, which means that SES index values ranged between 3.0 and 21.0 . This SES index was divided into quintiles and classified into (1) low SES (lowest quintile), (2) medium SES (middle three quintiles) and (3) high SES (upper quintile) ${ }^{(25)}$. Information about the region of residence was classified into (1) former West Germany and (2) former East Germany (including Berlin).

\section{Statistical analyses}

Mean, median, 5th and 95th percentiles for food and beverage consumption in $\mathrm{g} / \mathrm{d}$ were described separately for girls and boys. Distributions of individual consumption in proportion to the OMD-recommended amounts are presented using Box-Whisker plots with the inner box corresponding to the interquartile range around the median and the whiskers corresponding to the 5 th and 95 th percentiles.

Mean values with $95 \%$ CI for absolute amounts of food consumption in $\mathrm{g} / \mathrm{d}$ as well as the proportion of adolescents who achieved the OMD-recommended amounts (\%) were calculated in total and for categories of SES and region of residence. Differences in mean food group consumption by SES and region were tested using ANOVA. Differences in the proportion of adolescents who achieved the OMD-recommended amounts by SES and region were tested with the $\chi^{2}$ test.

To correct for deviations from the German population with regard to age (in years), sex, federal state (as of 31 December 2015), nationality (as of 31 December 2014) and parents' level of education (Microcensus 2013), as well as for differences in participation in EsKiMo II by parental SES, school type visited by the child and season, a weighting factor was applied in EsKiMo II. To take the cluster design of the study sample into account, the analyses were conducted using the survey procedures of SAS version 9.4 (SAS Institute Inc.). All analyses were stratified by sex.

\section{Results}

The present analysis included 727 girls and 626 boys. Twenty-three percent of the girls and $16 \%$ of the boys lived in families with a low SES and $14 \%$ of the girls and $21 \%$ of the boys in families with a high SES. One-sixth of the adolescents were from former Eastern Germany (Table 3).

Generally, mean and median food group consumption was higher among boys than girls (Table 4). The mean consumption of beverages among girls amounted to approximately $1700 \mathrm{ml} / \mathrm{d}$, whereas the mean consumption among boys was more than $2000 \mathrm{ml} / \mathrm{d}$. The main beverage was
Table 3 Basic characteristics of the study population of Eating Study as a KiGGS Module (EsKiMo) II ( $n$ 1353)

\begin{tabular}{|c|c|c|c|c|}
\hline & \multicolumn{2}{|c|}{ Girls } & \multicolumn{2}{|c|}{ Boys } \\
\hline & $n$ & $\%$ & $n$ & $\%$ \\
\hline & 727 & $48 \cdot 6$ & 626 & 51.4 \\
\hline \multicolumn{5}{|l|}{ Socio-economic status } \\
\hline Low & 76 & $22 \cdot 7$ & 53 & 16 \\
\hline Medium & 473 & $63 \cdot 6$ & 390 & 63.2 \\
\hline High & 167 & $13 \cdot 7$ & 175 & 20.9 \\
\hline \multicolumn{5}{|l|}{ Region of residence } \\
\hline Former East Germany & 249 & $16 \cdot 2$ & 216 & $16 \cdot 4$ \\
\hline Former West Germany & 478 & $83 \cdot 8$ & 410 & $83 \cdot 6$ \\
\hline
\end{tabular}

water which contributed to two-thirds of the total beverage consumption of girls and boys. Meanwhile, the contribution of soft drinks, juices and alcoholic beverages to total beverage consumption was about one quarter among girls and one-third among boys. Median consumption of meat/ meat products among girls was $74 \mathrm{~g} / \mathrm{d}$, whereas among boys, it was $114 \mathrm{~g} / \mathrm{d}$. Only the consumption of vegetables, fruits and tea was higher among girls than boys. Median consumption for fruits was $121 \mathrm{~g} / \mathrm{d}$ and for vegetables $167 \mathrm{~g} / \mathrm{d}$ among girls and $98 \mathrm{~g} / \mathrm{d}$ and $142 \mathrm{~g} / \mathrm{d}$, respectively, among boys.

Figure 1 shows the distribution (using Box-Whisker plots) of food group consumption among girls and boys expressed as proportions of the OMD-recommended amounts. The total amount of beverages consumed by most of the adolescents was above the minimum amount recommended. The median consumption of fruits, vegetables, starchy foods, milk/dairy products, eggs, fish and oil/ margarine/butter of adolescents was below the recommended amounts. This indicates that more than half of the adolescents did not achieve the recommendations for these food groups. For meat/meat products and unfavourable foods, the median consumption was far above the recommended amounts. More than half of the boys had a consumption of unfavourable foods twice as high as the recommended amounts (Fig. 1).

A comparison of the mean consumption of food groups by the SES of the family is presented in Table 5. Girls with a low SES consumed on average more meat/meat products than girls with a high SES $(103 \mathrm{~g} / \mathrm{d} v .67 \mathrm{~g} / \mathrm{d} ; P<0.01)$. The mean consumption of soft drinks was five times higher among girls with a low SES than those with a high SES $(314 \mathrm{~g} / \mathrm{d} v .62 \mathrm{~g} / \mathrm{d} ; P<0.001)$. Among boys, it was three times higher for those with a low SES compared with their counterparts with a high SES $(587 \mathrm{~g} / \mathrm{d} \quad v .188 \mathrm{~g} / \mathrm{d}$; $P<0.001)$. Meanwhile, boys with a high SES had a higher juice consumption than boys with a low SES $(155 \mathrm{~g} / \mathrm{d} v$. $254 \mathrm{~g} / \mathrm{d} ; P<0.05)$.

For most food groups, there were no statistical differences among SES groups regarding the proportion achieving the OMD-recommended amounts (Table 6). However, the proportion of boys who achieved the recommended amounts of fruit differed significantly by SES. Boys 
Table 4 Mean and distribution characteristics of total energy (kcal/d) and food consumption $(\mathrm{g} / \mathrm{d})$ among adolescents aged from 12 to $17 \mathrm{years}$ from Eating Study as a KiGGS Module (EsKiMo) II, stratified by sex ( $n$ 1353)*

\begin{tabular}{|c|c|c|c|c|c|c|c|c|}
\hline & \multicolumn{4}{|c|}{ Girls ( $n 727)$} & \multicolumn{4}{|c|}{ Boys ( $n$ 626) } \\
\hline & Mean & Median & P5 & P95 & Mean & Median & P5 & P95 \\
\hline Total energy intake $(\mathrm{kcal} / \mathrm{d})$ & 1866 & 1780 & 855 & 3315 & 2416 & 2221 & 1189 & 3976 \\
\hline Total food (except beverages) (g/d) & 1119 & 1052 & 522 & 1866 & 1340 & 1244 & 679 & 2323 \\
\hline Bread, savoury baked goods (g/d) & 135 & 122 & 38 & 284 & 160 & 145 & 47 & 318 \\
\hline Grain, pasta, rice $(\mathrm{g} / \mathrm{d})$ & 82 & 69 & 20 & 180 & 103 & 77 & 27 & 247 \\
\hline Breakfast cereals $(\mathrm{g} / \mathrm{d})$ & 11 & 3 & 0 & 47 & 21 & 5 & 0 & 91 \\
\hline Salty snacks $(\mathrm{g} / \mathrm{d})$ & 6 & 3 & 0 & 27 & 7 & 3 & 0 & 26 \\
\hline Vegetables $(\mathrm{g} / \mathrm{d})$ & 208 & 167 & 39 & 495 & 178 & 142 & 33 & 411 \\
\hline Fruits $(\mathrm{g} / \mathrm{d})$ & 163 & 121 & 13 & 407 & 136 & 98 & 5 & 410 \\
\hline Potatoes $(\mathrm{g} / \mathrm{d})$ & 65 & 53 & 8 & 166 & 83 & 65 & 11 & 208 \\
\hline Eggs $(g / d)$ & 15 & 11 & 0 & 48 & 21 & 14 & 2 & 59 \\
\hline Fats and oils $(\mathrm{g} / \mathrm{d})$ & 24 & 21 & 6 & 54 & 30 & 24 & 6 & 76 \\
\hline Milk/dairy products, cheese, curd (g/d) & 201 & 164 & 23 & 516 & 318 & 241 & 23 & 863 \\
\hline Meat/meat products $(\mathrm{g} / \mathrm{d})$ & 87 & 74 & 3 & 218 & 130 & 114 & 24 & 280 \\
\hline Fish $(g / d)$ & 9 & 4 & 0 & 31 & 13 & 6 & 0 & 43 \\
\hline Confectionery, cake (g/d) & 90 & 70 & 10 & 229 & 112 & 90 & 14 & 264 \\
\hline Total beverages $(\mathrm{g} / \mathrm{d})$ & 1727 & 1590 & 642 & 3141 & 2035 & 1887 & 932 & 3612 \\
\hline Tea $(\mathrm{g} / \mathrm{d})$ & 152 & 32 & 0 & 643 & 81 & 0 & 0 & 343 \\
\hline Coffee $(\mathrm{g} / \mathrm{d})$ & 26 & 0 & 0 & 182 & 29 & 0 & 0 & 214 \\
\hline Juice $(\mathrm{g} / \mathrm{d})$ & 177 & 77 & 0 & 671 & 243 & 115 & 0 & 879 \\
\hline Soft drinks (g/d) & 201 & 51 & 0 & 944 & 352 & 143 & 0 & 1500 \\
\hline Alcoholic beverages $(\mathrm{g} / \mathrm{d})$ & 22 & 0 & 0 & 118 & 46 & 0 & 0 & 317 \\
\hline Water $(\mathrm{g} / \mathrm{d})$ & 1150 & 1033 & 114 & 2516 & 1284 & 1143 & 100 & 2954 \\
\hline
\end{tabular}

P5, 5th percentile; P95, 95th percentile.

*Weighted figures except $n$ (= unweighted sample number).

with a low SES met the recommended amount of fruit more often compared with boys with a medium or high SES $(P<0.05)$.

Table 7 shows the mean consumption of foods by region of residence. Among girls from former West Germany, the mean consumption of total beverages was significantly higher than among girls from former East Germany $(1768 \mathrm{ml} v .1517 \mathrm{ml} ; P<0 \cdot 01)$. Considering the specific beverages, we observed that compared with girls from former East Germany, girls from former West Germany had a higher mean consumption of water (1215 $\mathrm{ml} v .814 \mathrm{ml} ; P<0.001)$ but a lower mean consumption of tea $(133 \mathrm{ml} v .247 \mathrm{ml} ; P<0 \cdot 05)$. In addition, girls from former West Germany had a higher mean consumption of grain, pasta, rice $(85 \mathrm{~g} v .68 \mathrm{~g} ; P<0.001)$, vegetables (214 g v. $179 \mathrm{~g} ; P<0.01)$ and meat/meat products $(90 \mathrm{~g} v$. $74 \mathrm{~g} ; P<0.01)$ and a lower consumption of breakfast cereals $(11 \mathrm{~g} v .16 \mathrm{~g} ; P<0.01)$ than girls from former East Germany. Among boys from former West Germany, the consumption of oils and fat was lower compared with counterparts from former East Germany $(37 \mathrm{~g} v .29 \mathrm{~g} ; P<0 \cdot 01)$.

There were differences in food consumption regarding the proportion of adolescents achieving or exceeding the recommended amounts of the OMD according to the region of residence. Girls from former West Germany achieved the recommended amount for vegetables significantly more often than girls from former East Germany (vegetables: $18.6 \% v \cdot 10 \cdot 4 \% ; P<0.05$ ). The recommended amount for total beverages was met significantly more often by girls from former West Germany (81.9\%) compared with girls from former East Germany $(71.7 \%$;
$P<0 \cdot 05)$. The recommended amounts for oil/margarine/ butter were achieved more often among boys from former East Germany $(38.8 \%)$ than among boys from former West Germany (23.8\%; $P<0.01)$ (Table 8).

\section{Discussion}

While the majority of adolescents in Germany consumed sufficient amounts of beverages, they did not achieve the recommended amounts of the OMD for most food groups. In particular, the consumption of fruits, vegetables, starchy foods and milk/dairy products of most adolescents aged 12-17 years in Germany was below the recommended amounts. The consumption of meat/meat products and unfavourable foods like sweets, pastries and sugar-sweetened beverages, which should be consumed sparingly, exceeded the recommended amounts. Though the total beverage consumption of the majority of adolescents was above the minimum amount recommended, a large part was reached through juices and soft drinks. Differences in food group consumption were also observed according to SES and region of residence; adolescents with a low SES had a higher soft drink consumption than those with a high SES. Girls from former West Germany more often achieved the recommended amount of vegetables compared with girls from former East Germany.

Our results are largely in line with results from the HELENA (Healthy Lifestyle in Europe by Nutrition in Adolescence) Study of a sample of European adolescents 
Adherence to food-based guidelines

(a)

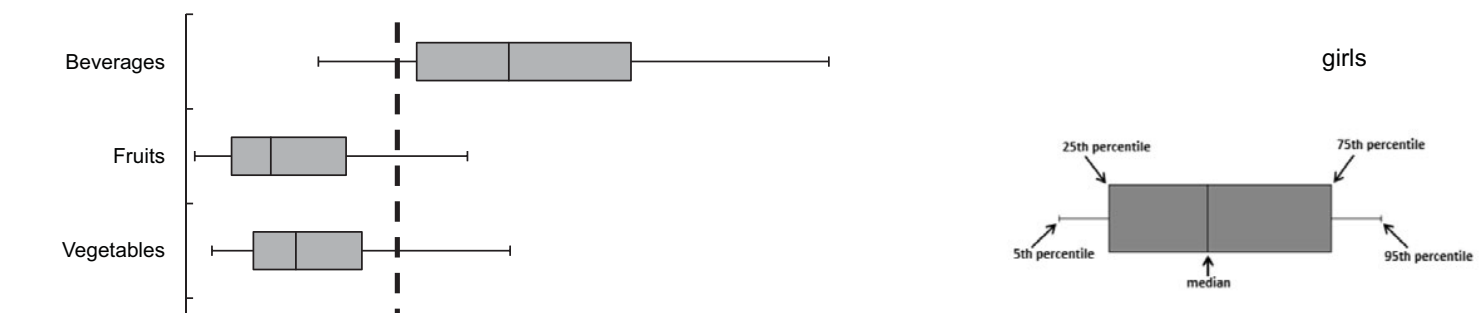

Unfavourable foods

Fish

Eggs

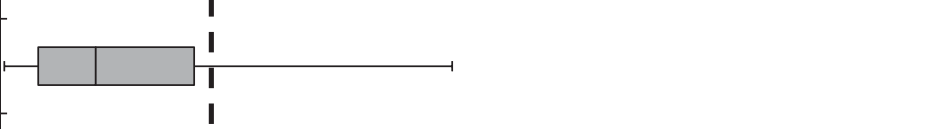

Fish

Oil/margarine/butter
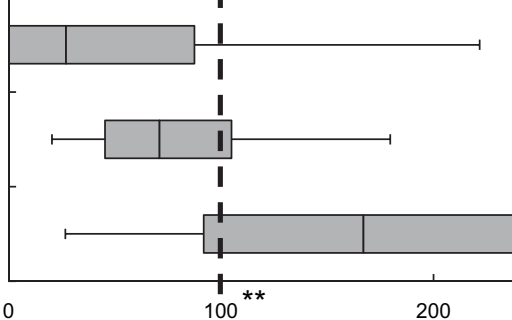

200

Percentage (\%) of recommended amounts

(b)

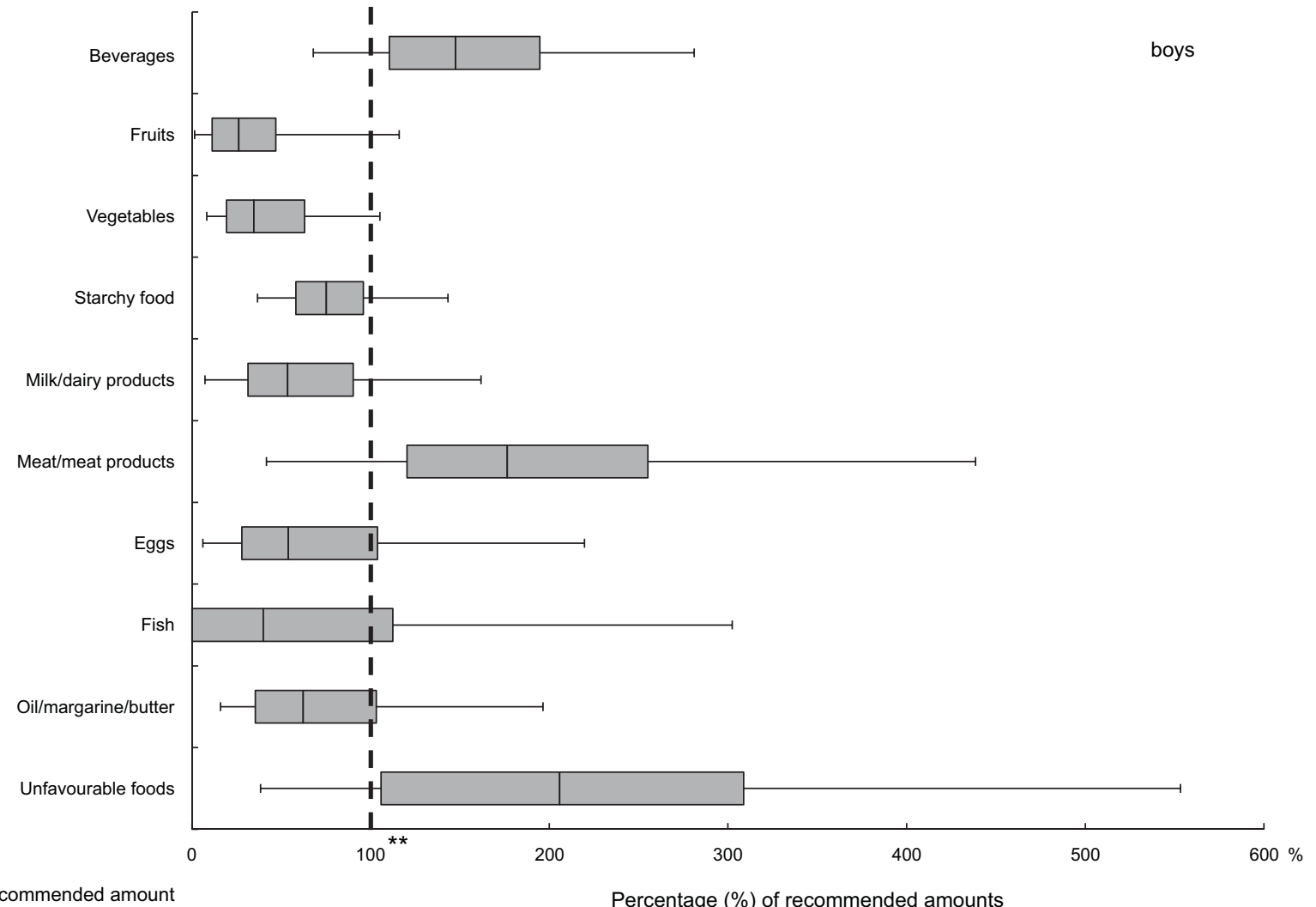

Fig. 1 Distribution of food consumption expressed as the proportion of the recommended amounts for an OMD among 12- to 17-yearold (a) girls and (b) boys in EsKiMo II ( $n$ 1353) (Box-Whisker plots*) * Box-Whisker plots with the inner box corresponding to the interquartile range around the median and the whiskers corresponding to the 5 th and 95th percentiles 
Table 5 Mean and $95 \% \mathrm{Cl}$ of food consumption (g/d) among adolescents from Eating Study as a KiGGS Module (EsKiMo) II by sex and socio-economic status (SES) ( $n$ 1334)

\begin{tabular}{|c|c|c|c|c|c|c|c|c|c|c|c|c|c|c|}
\hline & \multicolumn{7}{|c|}{ Girls (n716) } & \multicolumn{7}{|c|}{ Boys ( $n 618)$} \\
\hline & \multicolumn{7}{|c|}{ SES } & \multicolumn{7}{|c|}{ SES } \\
\hline & \multicolumn{2}{|c|}{ Low $(n 76)$} & \multicolumn{2}{|c|}{ Medium ( $n$ 473) } & \multicolumn{2}{|c|}{ High (n 167) } & \multirow[b]{2}{*}{$P+$} & \multicolumn{2}{|c|}{ Low (n 53) } & \multicolumn{2}{|c|}{ Medium ( $n$ 390) } & \multicolumn{3}{|c|}{ High (n 175) } \\
\hline & Mean & $95 \% \mathrm{Cl}$ & Mean & $95 \% \mathrm{Cl}$ & Mean & $95 \% \mathrm{Cl}$ & & Mean & $95 \% \mathrm{Cl}$ & Mean & $95 \% \mathrm{Cl}$ & Mean & $95 \% \mathrm{Cl}$ & $P \dagger$ \\
\hline Total foods (except beverages) & 1128 & 996,1259 & 1124 & 1072,1176 & 1087 & 1000,1173 & 0.771 & 1338 & 1127,1549 & 1304 & 1247,1360 & 1452 & 1325,1578 & 0.114 \\
\hline Bread, savoury baked goods & 130 & 105,155 & 134 & 124,144 & 139 & 124,155 & 0.798 & 157 & 130,184 & 157 & 148,167 & 171 & 153,188 & 0.367 \\
\hline Grain, pasta, rice & 81 & 64,97 & 83 & 75,90 & 87 & 76,98 & 0.789 & 88 & 66,110 & 97 & 88,106 & 124 & 98,149 & 0.070 \\
\hline Breakfast cereals & 9 & 5,13 & 12 & 9,14 & 15 & 11,19 & $0 \cdot 170$ & 12 & $-1,24$ & 23 & 15,31 & 23 & 18,28 & 0.205 \\
\hline Salty snacks & 7 & 5,10 & 6 & 5,8 & 4 & 3,6 & 0.061 & 5 & 1,9 & 7 & 6,9 & 7 & 5,8 & 0.622 \\
\hline Vegetables & 234 & 184,284 & 197 & 182,213 & 213 & 185,241 & 0.252 & 157 & 120,194 & 176 & 157,195 & 197 & 166,228 & 0.281 \\
\hline Fruits & 141 & 105,176 & 171 & 156,186 & 167 & 134,200 & 0.287 & 157 & 89,225 & 121 & 107,134 & 163 & 131,195 & 0.040 \\
\hline Potatoes & 67 & 53,80 & 67 & 60,73 & 56 & 49,62 & 0.049 & 88 & 49,128 & 83 & 74,92 & 78 & 68,88 & 0.732 \\
\hline Eggs & 18 & 13,23 & 15 & 13,17 & 13 & 10,16 & 0.177 & 27 & 19,35 & 21 & 18,24 & 18 & 15,21 & 0.038 \\
\hline Fats and oils & 24 & 21,27 & 25 & 23,27 & 23 & 20,27 & 0.776 & 28 & 21,35 & 30 & 27,32 & 31 & 27,34 & 0.773 \\
\hline $\begin{array}{l}\text { Milk/dairy products, } \\
\text { cheese, curd }\end{array}$ & 199 & 158,241 & 202 & 180,224 & 195 & 168,223 & 0.923 & 335 & 226,443 & 305 & 270,340 & 359 & 278,440 & 0.443 \\
\hline Meat/meat products & 103 & 82,124 & 86 & 78,95 & 67 & 56,79 & 0.003 & 149 & 112,186 & 127 & 117,137 & 127 & 114,139 & 0.497 \\
\hline Fish & 8 & 5,12 & 9 & 7,10 & 9 & 6,12 & 0.921 & 12 & 2, 22 & 13 & 10,15 & 12 & 10,15 & 0.924 \\
\hline Confectionery, cake & 83 & 62,105 & 96 & 87,104 & 80 & 67,93 & 0.091 & 91 & 71,110 & 117 & 108,127 & 117 & 104,131 & 0.041 \\
\hline Total beverages & 1783 & 1605,1962 & 1726 & 1627,1825 & 1676 & 1427,1925 & 0.746 & 2013 & 1723,2303 & 2095 & 1974,2216 & 1851 & 1694,2009 & 0.054 \\
\hline Tea & 138 & 78, 199 & 161 & 117, 205 & 126 & 89,164 & 0.514 & 70 & 26,114 & 79 & 53,106 & 80 & 49,112 & 0.929 \\
\hline Coffee & 30 & 5,56 & 25 & 15,34 & 25 & 1,49 & 0.922 & 37 & 9,66 & 28 & 18,37 & 28 & 15,41 & 0.808 \\
\hline Juice & 185 & 115,255 & 175 & 141,210 & 172 & 106,239 & 0.956 & 155 & 88,223 & 260 & 211,310 & 254 & 199,308 & 0.030 \\
\hline Soft drinks & 314 & 198,431 & 194 & 155,233 & 62 & 46,79 & $<0.001$ & 587 & 385,789 & 352 & 285,418 & 188 & 141,236 & $<0.001$ \\
\hline Alcoholic beverages & 11 & 4,18 & 28 & 10,46 & 15 & 6,23 & 0.215 & 39 & 5,72 & 52 & 35,68 & 40 & 20,59 & 0.572 \\
\hline Water & 1104 & 877,1331 & 1143 & 1052,1234 & 1275 & 1037,1514 & 0.512 & 1124 & 814,1435 & 1325 & 1209,1440 & 1261 & 1090,1433 & 0.440 \\
\hline
\end{tabular}

*Weighted figures except $n$ (= unweighted sample number), number of adolescents with missing SES: $n 19$ 
aged from 12 to 17 years $^{(26)}$. For most food groups, the deviations from the recommended amounts of the OMD observed in HELENA are in a similar range and the same direction as the ones observed in EsKiMo II. There seems to be a clear discrepancy between HELENA and EsKiMo II only for total beverage consumption, with a higher proportion of adolescents achieving the recommended amount for beverages in EsKiMo II compared with HELENA. This can be explained by differences in food group classification between both studies. In HELENA, only water, tea and coffee were assigned to the food group beverages, whereas in EsKiMo II, fruit and vegetable juices as well as soft and alcoholic drinks were also included.

Both the HELENA Study ${ }^{(26)}$ and EsKiMo II observed that the consumption of fruit and vegetables of adolescents was clearly below the recommended amount of the OMD. In other European countries, children and adolescents also did not reach the recommendation for fruit and vegetable consumption ${ }^{(26,27)}$. The WHO recommends a daily consumption of $400 \mathrm{~g}$ of fruit and vegetables for adolescents $^{(28)}$, which is lower than the recommended amount of the OMD. However, the mean consumption of $371 \mathrm{~g} / \mathrm{d}$ among girls is almost in accordance with the WHO recommendation. According to the ranking of the Health Behaviour in School-aged Children (HBSC) study for daily fruit consumption in Europe, the fruit consumption among adolescents living in Germany is at midrange, whereas countries like Greenland and Finland are at the bottom and Armenia and Albania are at the top of this ranking ${ }^{(29)}$. An improvement of fruit and vegetable consumption could be achieved by consuming one additional portion of fruit and one additional portion of vegetables daily.

In EsKiMo II, only about $20 \%$ of the adolescents reached the recommended amount for starchy foods. Shortcomings in the consumption of starchy foods of adolescents were also observed previously ${ }^{(26)}$.

Low consumptions of milk and dairy products by adolescents have been published previously ${ }^{(26)}$. The observation that even $<25 \%$ of the adolescents achieved the recommended amount for milk/dairy products indicates a need for action, especially because preliminary analysis of the nutrient intakes from EsKiMo II showed that Ca intake of the majority of adolescents is below the German nutrient recommendations (D-A-CH reference values) (unpublished results). Since milk and dairy products are an important Ca source ${ }^{(30)}$, a major cause of the deficits in Ca intake among adolescents may be the low consumption of milk and dairy products.

The median consumption of meat/meat products of adolescents in EsKiMo II was lower, as observed among adolescents in the HELENA Study ${ }^{(26)}$, but far above the recommended amount. A reduction of meat consumption is highly recommended. Current social developments and public discussions about vegetarianism, bio-industry, animal welfare, climate impact of meat consumption and 
Table 7 Mean consumption and $95 \% \mathrm{Cl}$ of foods (g/d) among adolescents from Eating Study as a KiGGS Module (EsKiMo) II by sex and region of residence ( $n$ 1353)

\begin{tabular}{|c|c|c|c|c|c|c|c|c|c|c|}
\hline & \multicolumn{5}{|c|}{ Girls ( $n 727)$} & \multicolumn{5}{|c|}{ Boys ( $n$ 626) } \\
\hline & \multicolumn{5}{|c|}{ Region of residence } & \multicolumn{5}{|c|}{ Region of residence } \\
\hline & \multicolumn{2}{|c|}{$\begin{array}{l}\text { Former East Germany } \\
\qquad(n 249)\end{array}$} & \multicolumn{2}{|c|}{$\begin{array}{l}\text { Former West Germany } \\
\qquad(n 478)\end{array}$} & \multirow[b]{2}{*}{$P+$} & \multicolumn{2}{|c|}{$\begin{array}{l}\text { Former East Germany } \\
\qquad(n 216)\end{array}$} & \multicolumn{2}{|c|}{$\begin{array}{l}\text { Former West Germany } \\
\qquad(n 410)\end{array}$} & \multirow[b]{2}{*}{$P+$} \\
\hline & Mean & $95 \% \mathrm{Cl}$ & Mean & $95 \% \mathrm{Cl}$ & & Mean & $95 \% \mathrm{Cl}$ & Mean & $95 \% \mathrm{Cl}$ & \\
\hline Total foods (except beverages) & 1097 & 1032,1163 & 1123 & 1070,1177 & 0.534 & 1369 & 1264,1473 & 1334 & 1273,1396 & 0.569 \\
\hline Bread, savoury baked goods & 126 & 115,137 & 137 & 127,147 & 0.163 & 160 & 145,176 & 159 & 149,170 & 0.919 \\
\hline Grain, pasta, rice & 68 & 63,74 & 85 & 78,92 & 0.000 & 98 & 74,123 & 104 & 94,113 & 0.687 \\
\hline Breakfast cereals & 16 & 13,19 & 11 & 8,13 & 0.009 & 22 & 15,28 & 21 & 14,27 & 0.861 \\
\hline Salty snacks & 5 & 3,7 & 6 & 5,8 & 0.337 & 6 & 4,7 & 7 & 5,8 & 0.328 \\
\hline Vegetables & 179 & 162,196 & 214 & 195, 233 & 0.007 & 176 & 142,210 & 179 & 162,195 & 0.889 \\
\hline Fruits & 184 & 161,208 & 158 & 144,172 & 0.053 & 162 & 135,189 & 131 & 114,149 & 0.056 \\
\hline Potatoes & 68 & 59,76 & 65 & 58,71 & 0.544 & 87 & 76,98 & 82 & 72,92 & 0.507 \\
\hline Eggs & 14 & 12,16 & 16 & 14,17 & 0.275 & 23 & 18,29 & 21 & 18,24 & 0.482 \\
\hline Fats and oils & 24 & 21,26 & 24 & 23,26 & 0.700 & 37 & 32,41 & 29 & 26,31 & 0.002 \\
\hline Milk/dairy products, cheese, curd & 220 & 188,252 & 197 & 177,217 & 0.222 & 305 & 256,355 & 320 & 281,360 & 0.633 \\
\hline Meat/meat products & 74 & 67,80 & 90 & 81,99 & 0.004 & 131 & 117,144 & 130 & 119,140 & 0.898 \\
\hline Fish & 8 & 6,9 & 9 & 7,10 & 0.330 & 10 & 8,12 & 13 & 10,16 & 0.082 \\
\hline Confectionery, cake & 93 & 82,105 & 90 & 80,99 & 0.644 & 126 & 110,142 & 110 & 101,119 & 0.079 \\
\hline Total beverages & 1517 & 1398,1636 & 1768 & 1670,1866 & 0.001 & 2050 & 1856,2244 & 2032 & 1924,2140 & 0.869 \\
\hline Tea & 247 & 141,353 & 133 & 103,164 & 0.039 & 104 & 69,139 & 77 & 55,99 & 0.186 \\
\hline Coffee & 25 & 5,45 & 26 & 16,35 & 0.948 & 43 & 21,65 & 26 & 18,33 & 0.130 \\
\hline Juice & 149 & 112,187 & 182 & 147,218 & 0.206 & 249 & 185,314 & 242 & 200,283 & 0.839 \\
\hline Soft drinks & 262 & 201,322 & 190 & 147,232 & 0.052 & 420 & 319,522 & 339 & 275,402 & 0.173 \\
\hline Alcoholic beverages & 20 & 12,28 & 22 & 9,36 & 0.772 & 49 & 26,71 & 45 & 32,59 & 0.806 \\
\hline Water & 814 & 706,921 & 1215 & 1114,1316 & $<0.001$ & 1185 & 989,1381 & 1304 & 1196,1411 & 0.287 \\
\hline
\end{tabular}

*Weighted figures except $n$ (= unweighted sample number).

†Significant differences between groups were tested using ANOVA. 
Table 8 Proportion of adolescents from Eating Study as a KiGGS Module (EsKiMo) II achieving the Optimized Mixed Diet (OMD)recommended amount by sex and region of residence $(n 1353)^{*}$

\begin{tabular}{|c|c|c|c|c|c|c|c|c|c|c|}
\hline & \multicolumn{5}{|c|}{ Girls ( $n$ 727) } & \multicolumn{5}{|c|}{ Boys (n 626) } \\
\hline & \multicolumn{5}{|c|}{ Region of residence } & \multicolumn{5}{|c|}{ Region of residence } \\
\hline & \multicolumn{2}{|c|}{$\begin{array}{c}\text { Former East } \\
\text { Germany }(n 249)\end{array}$} & \multicolumn{2}{|c|}{$\begin{array}{c}\text { Former West } \\
\text { Germany }(n 478)\end{array}$} & \multirow[b]{2}{*}{$P \dagger$} & \multicolumn{2}{|c|}{$\begin{array}{c}\text { Former East } \\
\text { Germany }(n 216)\end{array}$} & \multicolumn{2}{|c|}{$\begin{array}{c}\text { Former West } \\
\text { Germany }(n 410)\end{array}$} & \multirow[b]{2}{*}{$P+$} \\
\hline & $\%$ & $95 \% \mathrm{Cl}$ & $\%$ & $95 \% \mathrm{Cl}$ & & $\%$ & $95 \% \mathrm{Cl}$ & $\%$ & $95 \% \mathrm{Cl}$ & \\
\hline Fruits & $16 \cdot 3$ & $10 \cdot 2,22 \cdot 3$ & $15 \cdot 3$ & $11 \cdot 3,19 \cdot 3$ & 0.787 & $5 \cdot 6$ & $2 \cdot 2,9 \cdot 0$ & $6 \cdot 5$ & $3.5,9.5$ & 0.704 \\
\hline Vegetables & $10 \cdot 4$ & $6 \cdot 1,14 \cdot 6$ & $18 \cdot 6$ & $14 \cdot 3,22 \cdot 9$ & 0.011 & 7.9 & $3 \cdot 7,12 \cdot 7$ & $7 \cdot 1$ & $4 \cdot 2,10 \cdot 1$ & 0.761 \\
\hline Starchy food & $16 \cdot 1$ & $10 \cdot 3,21 \cdot 9$ & $22 \cdot 0$ & $17 \cdot 1,26 \cdot 9$ & 0.141 & 21.7 & $14.9,28.5$ & 19.5 & $15 \cdot 2,23 \cdot 9$ & 0.591 \\
\hline Meat/meat products & 69.6 & $62 \cdot 9,76 \cdot 4$ & 64.9 & $59 \cdot 2,70 \cdot 6$ & 0.299 & 79.6 & $72 \cdot 4,86 \cdot 8$ & 83.4 & $78 \cdot 7,88 \cdot 1$ & 0.371 \\
\hline Fish & $18 \cdot 8$ & $12 \cdot 6,25 \cdot 0$ & 20.4 & $15 \cdot 8,25 \cdot 0$ & 0.687 & $22 \cdot 7$ & $15 \cdot 8,29.5$ & 30.4 & $25 \cdot 1,35 \cdot 6$ & 0.089 \\
\hline Eggs & $18 \cdot 9$ & $12 \cdot 9,25 \cdot 0$ & $22 \cdot 8$ & $17 \cdot 8,27 \cdot 8$ & 0.334 & 28.5 & $19.5,37.5$ & $25 \cdot 0$ & $18 \cdot 6,31.5$ & 0.537 \\
\hline Milk/dairy products & $18 \cdot 2$ & $11.5,24.9$ & $15 \cdot 7$ & $11 \cdot 3,20 \cdot 1$ & 0.534 & 18.0 & $11 \cdot 7,24 \cdot 3$ & $19 \cdot 1$ & $13 \cdot 9,24 \cdot 4$ & 0.783 \\
\hline Oil/margarine/butter & $28 \cdot 3$ & $21 \cdot 7,35 \cdot 1$ & 28.9 & $24 \cdot 2,33 \cdot 7$ & 0.885 & 38.8 & $30 \cdot 5,47 \cdot 2$ & 23.8 & $19 \cdot 2,28 \cdot 3$ & 0.001 \\
\hline Beverages & $71 \cdot 7$ & $65.4,78 \cdot 0$ & 81.9 & $77 \cdot 1,86 \cdot 8$ & 0.011 & $77 \cdot 0$ & $68 \cdot 9,85 \cdot 1$ & 84.2 & $79 \cdot 6,88.7$ & 0.108 \\
\hline Unfavourable foods & $75 \cdot 6$ & $70 \cdot 8,80.5$ & 71.9 & $66 \cdot 2,77 \cdot 5$ & 0.315 & 77.9 & $68 \cdot 4,87 \cdot 4$ & $78 \cdot 1$ & $73 \cdot 1,83 \cdot 0$ & 0.970 \\
\hline
\end{tabular}

*Weighted figures except $n$ (= unweighted sample number).

†Significant differences between groups were tested using the $\chi^{2}$ test. $\ddagger$ Sweets, pastries, sugar-sweetened beverages.

feeding the increasing world population may lead to a reduction of meat consumption in the near future ${ }^{(31)}$.

The recommended amount of unfavourable food was also largely exceeded. An excessive consumption of energy-dense, nutrient-poor food is also seen in other European studies among adolescents ${ }^{(26,32)}$. As this food group mainly consists of foods with a high energy density and a low nutritive value, a reduction in the consumption of these foods or rather a shift of consumption from unfavourable to more favourable food groups like fruits, vegetables and unsweetened beverages is urgently needed.

Next to a comparison of the results from EsKiMo II and in the view of actual literature on food consumption of adolescents, a comparison with the results from EsKiMo I $(2006)^{(33)}$ is possible. This comparison indicates some changes in food consumption between 2006 and 2015-2017; the proportion of adolescents who achieved the recommended amounts of fruits, vegetables and milk/dairy products decreased over time. However, the proportion of adolescents who achieved the recommended amount of starchy foods has increased. The proportion of the recommended amount achieved for beverages, unfavourable foods and fish was similar in EsKiMo I and EsKiMo II. However, it should be considered that the recommended amounts of the OMD for the food groups fruits, vegetables, milk/ dairy products and starchy foods have been changed between 2006 and 2015(20). Additional analysis evaluating the food group consumption within EsKiMo I according to the actual OMD recommendations also shows a decrease in the proportion of adolescents achieving the recommended amount for fruits and milk/dairy products between both EsKiMo studies, and also the proportion of adolescents achieving the recommended amount of starchy foods decreased when using recalculated data for EsKiMo I (data not shown).
In both EsKiMo I ${ }^{(33)}$ and EsKiMo II, sex differences in food consumption and in adherence to the food-based dietary guidelines have been observed. In both studies, absolute food consumption was higher among boys, conforming to the mainly higher requirements for boys than for girls. However, compared with girls, a lower proportion of boys achieved the recommended amounts of fruit and vegetables. Furthermore, boys showed a higher consumption of soft drinks. Generally, a poorer dietary quality among boys has already been reported in several studies conducted among adolescents and young adults in Belgium, New Zealand and the USA ${ }^{(32,34,35)}$. Reasons for the differences between boys and girls might be differences in preferences, amongst others. Girls have a higher affinity for fruits and vegetables and perceive a lower barrier to their consumption $^{(36)}$. Sex differences in fruit and vegetable consumption were also seen among adults living in Germany ${ }^{(37,38)}$.

The results of EsKiMo II indicate a poorer dietary quality for adolescents with a low SES. The strongest social gradient is seen for soft drinks; boys and girls with a low SES have a significant higher consumption of soft drinks than adolescents with a high SES. This is in line with previous studies among adolescents, for example, the KiGGS Wave 1 and HBSC studies conducted in Germany and European Countries, respectively ${ }^{(11,12,39)}$. Girls with a low SES have a significantly higher consumption of meat/meat products compared with girls with a high SES. A similar association between meat consumption and SES has already been reported for other populations ${ }^{(40)}$. However, the association between SES and the consumption of fruit ${ }^{(8,9)}$ and vegetables ${ }^{(8-10)}$ observed in previous studies, also among adults ${ }^{(37,38)}$, is not seen in EsKiMo II. This may be due to projects focused on the improvement of fruit and vegetable consumption, such as the EU school fruit and vegetable 
schemes that reach adolescents from all social backgrounds or projects focusing on socially disadvantaged adolescents conducted in the last decade ${ }^{(41)}$.

To our knowledge, this is the first investigation of food consumption including a comparison with food-based dietary guidelines among adolescents by region of residence in Germany. Several differences in consumption were observed for former East and West Germany. These differences are especially seen among girls. One explanation for these differences may be that former East Germany has more rural regions, a different SES structure and a longer tradition of school meal supply and a higher utilisation of school meals ${ }^{(42)}$, which may contribute to the observed differences and may have a larger impact among girls. In Germany, the availability and usage of school meals have grown in recent years. In addition, there is a programme to improve the quality of these meals ${ }^{(43)}$. This development may contribute to preferable changes in the diet of adolescents.

This study has strengths and limitations. A limitation is that information on food consumption was collected retrospectively and based on self-reports, which might lead to recall bias. Also, particular foods may be under-reported (e.g. confectionery, sugar-sweetened beverages) or overreported (e.g. fruits and vegetables) due to social desirability. As a consequence, the deficits of food consumption may be larger. In addition, the assignment of food groups is very complex as composed foods can be included as such in a food group, that is, bread and cakes, while other composed foods, which cannot be assigned to a single food group, were decomposed to their ingredients, being assigned into the corresponding food groups. Although this process was highly standardised, conducted by a nutritionist and double-checked, some level of misclassification of single foods cannot be excluded. The consumption of fruits might be slightly higher than reported, as cakes were not decomposed into food groups. In case of disaggregating particular cakes containing fruits into their ingredients, there might be a shift in the allocation of foods to food groups from unfavourable foods to fruits. There are also some restrictions in comparison with the OMD amounts. The definition of food groups of the OMD is relatively broad and lacks some details about which particular foods should be included or excluded. Although the OMD does not specifically mention this, we assumed that the recommended amounts of the OMD refer to amounts of foods as consumed (not as raw quantities). These amounts were used as the basis for our calculations. In addition, the inclusion of sugar-sweetened beverages in the total amount of beverages as well as in the food group of the unfavourable foods is ambiguous. So, the consumption of fruit and vegetables expressed as proportion of recommended amounts may be underestimated, and evaluation of total beverage consumption does not differentiate between the contribution of preferable and non-preferable beverages. This study gives an overview of the recent food intake of adolescents in
Germany and its distribution in subgroups. It is mainly a descriptive analysis without intending to detect causal relationships or to test a priori hypotheses. Nevertheless, many $P$-values are presented, and the implication of multiple testing should be considered. However, for this explorative situation using variables which are not completely independent (food groups as well as SES/region), a correction for multiple testing may be difficult and not appropriate, as suggested in literature ${ }^{(44,45)}$. Nevertheless, the significance of results should be interpreted with caution. The strength of the study is that it was conducted nationwide with a large representative sample and reflects the food consumption of adolescents in Germany.

The results underline the need for interventions that improve the food consumption of adolescents, especially to accomplish the shift from a high consumption of unfavourable foods and meat to a higher consumption of fruit, vegetables, foods with complex carbohydrates and milk/ dairy products or adequate substitutes. This is a major challenge for all public health professionals. In 2008, the national action plan 'IN FORM - German national initiative to promote healthy diets and physical activity' was launched with the aim to promote a healthy lifestyle with a balanced diet and sufficient exercise in all living environments. Already developed initiatives and strategies from federal and state governments and municipalities were complemented and deepened. Most measures, projects or recommendations take place in the living environment as a way to make changes in behaviour easier in everyday life. For instance, projects in schools can reach the whole generation of young people of all social levels ${ }^{(41)}$. However, the observed differences in food consumption between EsKiMo I and II indicate that the existing measures may have led to only limited improvements in preferable food consumption so far. Further approaches to promote a healthy diet, such as easy to understand front-of-package labelling, a restriction on the promotion of unhealthy foods through all media and price policies for healthy and unhealthy foods, should be considered.

In conclusion, the current overview of the food consumption of adolescents in Germany shows that the consumption of fruit and vegetables is far below the recommendation, whereas the consumption of meat and unfavourable foods, like sugar-sweetened beverages and confectionery, is too high. Social disparities are seen in the consumption of soft drinks. This indicates that approaches to promote healthy diets should be continued and the focus on social inequalities should be strengthened.

\section{Acknowledgements}

Acknowledgements: First, we would like to thank the adolescents and their parents for their participation in EsKiMo II. We are also very grateful to the KiGGS staff and 
colleagues at the Robert Koch Institute who supported the conduction of the survey. We would especially like to thank the interviewers of EsKiMo II for their excellent work during the 2-year data collection phase. Financial support: The nutrition survey EsKiMo II was funded by the German Federal Ministry of Food and Agriculture (BMEL) on the basis of a resolution of the German Bundestag. Funding is provided by the German Federal Agency for Agriculture and Food (BLE), funding code 2814HS004. Conflict of interest: 'None.' Authorship: G.B.M.M. conceptualised, designed, managed and supervised the study. A.K.B. analysed the data for the manuscript, wrote the first draft and coordinated the field work of the study. C.L.B. coordinated the study. M.H. managed the study data. A.K.B., C.L.B., M.H. and F.L. assured consistency and quality control of the data. All authors contributed to analysis concepts and have read and approved the final manuscript. Ethics of human subject participation: This study was conducted according to the guidelines laid down in the Declaration of Helsinki, and all procedures involving study participants were approved by the ethics committee of the Hannover Medical School and the German Federal Commissioner for Data Protection and Freedom of Information as an amendment of KiGGS Wave 2 (No. 2275-2014). A written informed consent was obtained from all participants aged 14 years or older and all parents/caregivers.

\section{References}

1. Mozaffarian D (2016) Dietary and policy priorities for cardiovascular disease, diabetes, and obesity: a comprehensive review. Circulation 133, 187-225.

2. Ebbeling CB, Pawlak DB \& Ludwig DS (2002) Childhood obesity: public-health crisis, common sense cure. Lancet 360, 473-482.

3. Ellrott T (2009) Entwicklung des Essverhaltens im Kindes- und Jugendalter [Development of eating behaviour in childhood and adolescence]. In Kinderernährung Aktuell Schwerpunkte für Gesundheitsförderung und Prävention, pp. 66-77 [M Kersting, editor]. Sulzbach: Umschau Zeitschriftenverlag.

4. Kelder SH, Perry CL, Klepp KI et al. (1994) Longitudinal tracking of adolescent smoking, physical activity, and food choice behaviors. Am J Public Health 84, 1121-1126.

5. Drewnowski A (2009) Obesity, diets, and social inequalities. Nutr Rev 67, S36-S39.

6. Schienkiewitz A, Brettschneider A-K, Damerow S et al. (2018) Overweight and obesity among children and adolescents in Germany. Results of the cross-sectional KiGGS Wave 2 study and trends. $J$ Health Monit 3, 15-22.

7. Singh GK, Siahpush M \& Kogan MD (2010) Rising social inequalities in US childhood obesity, 2003-2007. Ann Epidemiol 20, 40-52.

8. Borrmann A \& Mensink GBM (2015) Fruit and vegetable consumption by children and adolescents in Germany. Results of KiGGS wave 1. Bundesgesundheitsblatt Gesundheitsforschung - Gesundheitsschutz 58, 1005-1014.

9. Fismen AS, Smith OR, Torsheim T et al. (2016) Trends in food habits and their relation to socioeconomic status among nordic adolescents 2001/2002-2009/2010. PLoS One 11, e0148541.
10. Niven P, Scully M, Morley B et al. (2014) Socio-economic disparities in Australian adolescents' eating behaviours. Public Health Nutr 17, 2753-2758.

11. Hanson MD \& Chen E (2007) Socioeconomic status and health behaviors in adolescence: a review of the literature. J Behav Med 30, 263-285.

12. Mensink GBM, Schienkiewitz A, Rabenberg M et al. (2018) Consumption of sugary soft drinks among children and adolescents in Germany. Results of the cross-sectional KiGGS Wave 2 study and trends. J Health Monit 3, 31-37.

13. Holstein BE, Damsgaard MT, Due P et al. (2020) Intake of sugar sweetened soft drinks among adolescents: trends and social inequality in Denmark 2002-2018. Nutr Health 26, 3-8.

14. Moosburger R, Lage Barbosa C, Haftenberger M et al. (2020) Fast food consumption among 12- to 17 -year-olds in Germany - results of EsKiMo II. J Health Monit 5, 3-18.

15. Klemm K \& Zorn D (2017) Gute Ganztagsschule für alle. Kosten für den Ausbau eines qualitätsvollen Ganztagsschulsystems in Deutschland bis 2030 [Good AllDay School for Everyone. Costs for the Expansion of a High-Quality All-Day School System in Germany until 2030]. Gütersloh. https://www.bertelsmann-stiftung.de/ fileadmin/files/Projekte/27_In_Vielfalt_besser_lernen/Gute_ Ganztagsschule_01.pdf (accessed date 2021).

16. Kurth BM, Kamtsiuris P, Holling H et al. (2008) The challenge of comprehensively mapping children's health in a nation-wide health survey: design of the German KiGGSStudy. BMC Public Health 8, 196.

17. Mensink GBM, Bauch A, Vohmann C et al. (2007) EsKiMo - the nutrition module in the German health interview and examination survey for children and adolescents (KiGGS). Bundesgesundheitsblatt Gesundheitsforschung - Gesundheitsschutz 50, 902.

18. Lage Barbosa C, Brettschneider A-K, Haftenberger $\mathrm{M}$ et al. (2017) Comprehensive assessment of food and nutrient intake of children and adolescents in Germany: EsKiMo II - the eating study as a KiGGS module. BMC Nutr 3, 1-7.

19. Brettschneider A-K, Lage Barbosa C, Haftenberger M et al. (2018) The nutrition survey EsKiMo II - design, execution and public health policy relevance. Ernaebrungs Umsch International 65, 80-88.

20. Kersting M, Kalhoff H \& Lücke T (2017) From nutrients to food and meals: the concept of the optimized mixed diet for children and adolescents in Germany. Aktuelle Ernährungsmedizin 42, 304-315.

21. Mensink GBM, Haftenberger M \& Thamm M (2001) Validity of DISHES 98, a computerised dietary history interview: energy and macronutrient intake. Eur J Clin Nutr 55 , 409-417.

22. Ocké M, de Boer E, Brants H et al. (2012) PANCAKE Pilot study for the assessment of nutrient intake and food consumption among kids in Europe. EFSA Supporting Publications 9, 339E.

23. Van Kappel AL, Amoyel J, Slimani N et al. (1995) EPIC-SOFT Picture Book for the Estimation of Food Portion Sizes. Lyon: International Agency for Research on Cancer.

24. Truthmann J, Mensink GBM \& Richter A (2011) Relative validation of the KiGGS Food Frequency Questionnaire among adolescents in Germany. Nutr J 10, 133.

25. Lampert T, Hoebel J, Kuntz B et al. (2018) Socioeconomic status and subjective social status measurement in KiGGS Wave 2. J Health Monit 3, 108-125.

26. Diethelm K, Jankovic N, Moreno LA et al. (2012) Food intake of European adolescents in the light of different food-based dietary guidelines: results of the HELENA (Healthy Lifestyle in Europe by Nutrition in Adolescence) Study. Public Health Nutr 15, 386-398.

27. Lynch C, Kristjansdottir AG, Te Velde SJ et al. (2014) Fruit and vegetable consumption in a sample of 11-year-old 
children in ten European countries - the PRO GREENS crosssectional survey. Public Health Nutr 17, 2436-2444.

28. World Health Organization (WHO) (2003) Diet, Nutrition and the Prevention of Chronic Diseases. Report of a Joint WHO/FAO Expert Consultation. Geneva: WHO.

29. Inchley J, Currie D, Young T et al. (2016) Health Behaviour in School-aged Children (HBSC) Study: International Report from the 2013/2014 Survey. Health Policy for Children and Adolescents, No. 7. Copenhagen, DK: World Health Organization.

30. Food and Agriculture Organization of the United Nations (FAO) (2013) Milk and Dairy Products in Human Nutrition. Rome: FAO.

31. Sanchez-Sabate R \& Sabaté J (2019) Consumer attitudes towards environmental concerns of meat consumption: a systematic review. Int J Environ Res Public Health 16, 1220.

32. Vandevijvere S, De Vriese S, Huybrechts I et al. (2009) The gap between food-based dietary guidelines and usual food consumption in Belgium, 2004. Public Health Nutr 12, 423-431.

33. Mensink GBM, Heseker H, Richter A et al. (2007) Forschungsbericht - Ernährungsstudie als KiGGS-Modul (EsKiMo) [Research Report - Eating Study as a KiGGS Module (EsKiMo)]. Berlin: Robert Koch-Institut, Universität Paderborn.

34. Conner TS, Thompson LM, Knight RL et al. (2017) The role of personality traits in young adult fruit and vegetable consumption. Front Psychol 8, 119.

35. Olson JS, Hummer RA \& Harris KM (2017) Gender and health behavior clustering among U.S. young adults. Biodemography Soc Biol 63, 3-20.

36. Brug J, Tak NI, te Velde SJ et al. (2008) Taste preferences, liking and other factors related to fruit and vegetable intakes among schoolchildren: results from observational studies. $\mathrm{Br}$ J Nutr 99, S7-S14.

37. Heuer T, Krems C, Moon K et al. (2015) Food consumption of adults in Germany: results of the German National Nutrition Survey II based on diet history interviews. $\mathrm{Br} \mathrm{J}$ Nutr 113, 1603-1614.

38. Mensink GBM, Truthmann J, Rabenberg M et al. (2013) Fruit and vegetable intake in Germany. Results of the German Health Interview and Examination Survey for Adults (DEGS1). Bundesgesundheitsblatt - Gesundheitsforschung Gesundheitsschutz 56, 779-782.

39. Vereecken CA, Inchley J, Subramanian SV et al. (2005) The relative influence of individual and contextual socioeconomic status on consumption of fruit and soft drinks among adolescents in Europe. Eur J Public Health 15, 224-232.

40. Chan EY \& Zlatevska N (2019) Jerkies, tacos, and burgers: subjective socioeconomic status and meat preference. Appetite 132, 257-266.

41. Federal Ministry of Food and Agriculture (BMEL) (2018) IN FORM - Deutschlands Initiative für gesunde Ernäbrung und mebr Bewegung - Eine Zwischenbilanz [IN FORM Germany's Initiative for Healthy Eating and More Movement - An Interim Balance]. Berlin: BMEL.

42. Heide K, Brettschneider A-K, Lehmann F et al. (2019) Utilization of school meals. Results from the nationwide nutrition survey EsKiMo II. Ernaebrungs Umschau International 66, 92-99.

43. Arens-Azevêdo U, Bölts M, Girbardt R et al. (2014) DGE Quality Standard for School Meals. Bonn: German Nutrition Society.

44. Bender R \& Lange S (1999) Multiple test procedures other than Bonferroni's deserve wider use. BMJ 318, 600-601.

45. Perneger TV (1998) What's wrong with Bonferroni adjustments. BMJ 316, 1236-1238. 